\title{
The Development of Students' Cross-cultural Competence in the Conditions of Transitive Society
}

\author{
Boris Takhokhov* \\ North Ossetian state university named after K.L. Khetagurov, Department of pedagogy and \\ psychology, 362025 Vladikavkaz, Russia
}

\begin{abstract}
The study is devoted to the substantiation of the need for the development of students' cross-cultural competence at the time of transitive society: it demonstrates that the current stage of social development has an actualizing effect on the psychology of the individual due to the fact that the society and its individual representative resemble the image of two-faced Janus, when one side of the person is turned to the past and the other - to the future. Under these conditions cross-cultural competence as an activity-oriented concept, the aim of which is a social adaptation of the student's personality through the acculturation in the multicultural world, becomes a psychological and pedagogical imperative. It is noted that the cross-cultural competence in the era of postmodernism and globalization contributes to the education of students in the spirit of openness, pluralism of tastes, opinions and tolerance; at the cognitive level it is a significant expansion of cognitive space, a better understanding of both personal and other cultures. The Methodological Base of the Study: the humanistic paradigm in education and social Sciences, system, activity, cultural and personality-oriented approaches. The Research Methods: analysis and synthesis, systematization and classification, observation and generalization.
\end{abstract}

The understanding of the vector of psychological and pedagogical education development in a transitive society is extremely relevant, it is caused by the general interest in the processes that unfold in society and relate to each individual, reminding him that he is determined by at least two streams of influence: the first is associated with the origin and socialization, diverse relationships with the family order, the environment, territorial community, cultural and historical roots, the second is associated with the trend of modern civilization development, which is dominated by the values of postmodern personality, emerging in the era of globalism. In short, the space of life, in which the individual is immersed, is a continuum of different cultures, ambiguous influences, a symbiosis of traditions and innovations. No less topicality, the chosen theme comes from the relevance of the general problems of the research forum - the formation of cross-cultural competence of students for whom the above-mentioned influences are more than tangible and vital:

\footnotetext{
* Corresponding author: borisbit@mail.ru
} 
knowledge, skills and life skills in the "universal community", as we call globalization, efficient interaction with representatives of other cultures and customs is the key to the survival of both the individual and the whole nation, which has its own unique face in the diversity of other nations and cultures.

The certain set of the publications, containing different points of view on the considered problem is accumulated in the scientific and pedagogical literature. It is worth mentioning the scientific studies, devoted to questions of ethnic manifestations of people: A.J. Umaña-Taylor, S. M. Quintana, R. M. Lee, et al. [1], G. Soldatova, L. Shaigerova [2], R.Z. Peng, W.-P. Wu [3]; the works by W. Wang, M. Zhou [4], R. Chi, D. Suthers [5], I. Lianaki-Dedouli, J. Plouin [6], S.B. Dagbaeva [7] present observations on the peculiarities of interaction between representatives of different ethnic groups. The works by Csizmadia, A. Rollins, J. P. Kaneakua [8], D.S. Kornienko, I.V. Gaidamashko, S.L. Kandibovich [9], A.Y. Chung, A.Y. From [10] characterize the existing practices of the individual's worldview formation under the influence of national and civilizational value orientations. It is impossible to ignore such studies, which present the experience of integrated learning and education of students on the material of dominant views, characteristic of the postmodern era and globalization [11-14]. In the works by T.D. Jules [15], C.M. Brown, W. Ling [16], N. M. Lebedeva, A.N. Tatarko, J. Berry [17] various approaches to the socialization of the individual, taking into account ethnic identity and cultural diversity are analyzed.

A number of scientific and practical projects, interesting from the standpoint of our understanding of the problem, are published on programs aimed at the formation of ethnocultural competence and tolerant attitude to the diversity of cultures and their representatives [17,18]. The research in line with the integration and coordination of educational and training programs and methods for the development of ethnic identity of students, their orientation to the intercultural worldview and behavior is carried out by I.V. Abakumova, Z.I. Brizhak, Z.V. Masaeva [19] и P.M. Shamionov, N. Zh. Sultaniyazova [20].

The mentioned publications are a manifestation of theorists, practical teachers and psychologists' keen interest to different sides of the current stage of the society and individual personality development, and the interaction of different cultures. However, the analysis of available publications, theoretical concepts gives us rights to state that the problem of the students' cross-cultural competence development in a transitive society has not received more or less sufficient research coverage yet.

In the context of this problem, we suppose that the nowadays state of such Sciences as Ethnopedagogics and Ethnopsychology must be researched, because the logic of the article text determines the actualization of these Sciences.

The leading component in both terms is "ethnos", in this article we take the view of Max Veber and Martin Heidegger, they interpreted this phenomenon as a certain community of people with some generic properties, among which there also are common properties as: origin, language, territory and traditions. However, it should be borne in mind that in the process of a broader concept formation, of what a nation is, the cultural identity of ethnic groups and nations is equalized, in other words, when we say "nation", we mean nothing but a "melting pot" in which all are mixed and form some artificial community of people.

The "Psychological and Pedagogical Boom" in theory and practice arose as a consequence of democratic processes in society, freedom from ideological dictatorship and a unified approach not only to the individual, but to entire nations as well.

There are two opposing trends in the world today: a) globalization, which to a certain extent unifies, likens peoples, cultures and civilizations; b) ethnic Renaissance, which is characterized by the appeal of peoples to their origins and root causes as a reluctance to be 
like everything and everyone.

The Globalization has touched everything, they captured almost everyone and as follows from the figurative expression of S. Jobs, "we all live in a big village", everything is interconnected and unified. If we look around, we will actually see a lot in common in the material and spiritual spheres. For example, cars, produced in the leading countries of the world, travel on the roads of different continents, phones and all other appliances, have become a daily reality for all nations, regardless to the place of residence and production. The same can be said about the highest spiritual, cultural, scientific and educational achievements, which know neither barriers nor borders. All this, is Globalization, which at the same time affirms in the minds and behavior of people that are unacceptable by some nations, in such cases, the resistance which takes place in different countries is more natural. Unfortunately, the virtue has not yet become universal, and modern civilization with material innovations has the destruction effect, turning all people into consumers.

Each nation has its own unique history, psychology, its ideals, which they firmly try to preserve, and they can be revealed by different scientific disciplines, among which the leading place belongs to Ethnopsychology and Ethnopedagogics.

Modern Ethnopsychology and Ethnopedagogics as independent Sciences are aimed to: a) draw the attention of the human society to the fact, that each ethnic community has its own laws and mechanisms of mental typology manifestation, value orientations and behavior, b) investigate the constantly developing reflection of ethnic groups aimed at selfknowledge and self-presentation.

In this regard, the further development of the conceptual apparatus of the "wandering" myths and stories theory should be considered legitimate, it reveals the differences and similarities that exist in the life experience of certain ethnic groups. The description of ethnopedagogic experience in terms of modern pedagogy should be supplemented by the results of other research and operational procedures, in particular, by comparing the components of cultural traditions of ethnic groups, living in the local geographical space, on the one hand, and being in spatial distance from each other - on the other hand. This science is closely connected with the history of peoples, culture, values and ideals, accumulating the existing ideas on how to coexist generations, integrate, unite the group and strengthen the intra-group solidarity. The ethnic ties that bind people at the level of self-consciousness and subconsciousness have a high protective potential and are considered to be the universal unifying principles that perform an integrative function. Ethnic identity is determined by socio-political factors and, as a result of social mythmaking, it exists on purely pragmatic grounds.

Myths and fairy tales have another feature - they carry the standards of moral normative behavior. Democritus in his ethics and many philosophers and psychologists after him noted that a person is distinguished by the presence of a moral sense of conscience, which is summarized in the word "must": "It is necessary to refrain from misconduct, not out of fear, but out of a sense of duty". The duty acquires special significance for the analysis of the problem of violence, representing the mode of the individual's perception of the world, demonstrating the variants for mutual obligations of a person and an ethnic group. The individual makes demands on the world around him, and in his turn is ready to assume obligations to him. The duty associated with internal and external factors is found in such national feelings as pride, admiration, anger, gratitude, resentment, reproach, revenge; manifestations of obligation there may be regulations, prohibitions and related advice, teaching, call, order, pleading, etc.

Nowadays, Ethnopsychology and Ethnopedagogics are aimed to contribute to the solution of two fundamental problems: a) finding the means of compensation for psychosocial overload in the arsenal of Folk Pedagogy, b) helping the common man in understanding the negative consequences of ethnocentrism and self-denial, including those 
associated with tense interethnic relations, which are formed depending on many factors. There is a dynamic unity of inter-ethnic identification and isolation during the stable period and positive development, but during social instability, these relations regress and the stage is taken by the inter-ethnic aggression and strengthening of ethnocentrism, which are manifested not only in the historically arisen environment of the ethnic group itself, but also in the relations of individual representatives of the ethnic group with other groups, which causes negative reactions of others or suppresses the self-esteem and ethnic wealth of those who are affected. In this case, the opinion of the classification of their "social counterparts" in the category of "strangers", "enemies" begins to dominate within the ethnos. It should be noted that it is not uncommon for inter-ethnic relations to develop self-denial, which requires reflection and the search for a universal way out of this recurring inter-ethnic tension. This phenomenon is connected with personal ethnic attitudes - a system of sociocultural relations to the nature, image, culture, morality, behavior, habits of representatives of their own and other ethnic groups, which begin to play a leading role.

The socialization of modern students is completely painless in conditions, dominated by a national set of laws and relevant rules - regulations on the cohabitation of people, regardless of their ethnic origin. Despite the fact that there are frequent cases of national inequality, harassments on a national basis, as a rule, the state monitors the rule of law throughout the country. But the multicultural and multi-ethnic composition of the population of the country leaves its mark on the psychology of personality, in the minds of every person there is an image not only of their nationality, but of other ethnic groups as well. For example, the spirit and ideology of internationalism, which was the cornerstone of the worldview of many people in the 20th century, led them to a common fight against fascism in different countries, under common flags - it was months and years of truly great brotherhood of Nations.

The ideology of likening people in the first half of the 20th century permeated almost all countries, ethnic psychology was also imbued with this doctrine. This attitude - image, on the one hand, to a certain extent was historically conditioned, on the other hand - arose and passed certain stages of its formation and development under the influence of the environment in which the person was socialized.

It is advisable to consider the assimilation of ethnic information and features of ethnic self-identification in the context of mentality - properties, formed in a certain way of consciousness to reflect the ethnic picture of the environment. Mentality is connected with the internal, unconscious complexes formed in the process of adaptation of the ethnic group in the social and natural environment and perform in ethnic culture the role of the main mechanisms of the ethnic group's existence in the environment. These unconscious images are part of the ethnic constants' system and create an exclusive inner intellectual and moral world characteristic of a certain group. The category of mentality gives an idea of the ethnic group's mental composition in socio-political and psychological contexts. Ethnic mentality is manifested in the leading moods, characteristic features of world perception, the system of moral values, norms and principles of education, in the forms of interpersonal interaction and specific acts of self-organization of the ethnic group. It is this category that sheds light on group stereotypes, attitudes, prejudices, that allows us to characterize both our own and other ethnic groups.

It is believed that ethnic characteristics are the leading among many social categories: according to C. G. Jung, the ethnic category appeared after the global category of Homo sapiens.

Until recent years, in the modern hierarchy of values, formed in schoolchildren, the main disputes were around the dilemma - universal and national, however, having long roots in the history of Russian philosophy in the form of Westerners and Slavophiles. At the same time, we can agree with the opinion that the universal and national in the formation of 
personal culture, complement each other: the spiritual life of a person becomes deeper and richer under the influence of these values' combination. Ethnopedagogic and Ethnopsychological studies bring up national feelings: maternal (language, nationality, song, fairy tale) and paternal (duty, rights, organization of society and state). The connection of national feeling with moral values in general is extremely important, because the national feeling education is not only to reveal and confirm its spiritual meaning, but it is a part of the spiritual education in General.

Peoples' spiritual and cultural traditions, their historical past, educational ideals, cultural and historical symbols-images, allowing to strengthen the national dignity of some people, contribute to their rapprochement and mutual enrichment, without compromising the dignity of others, that is why, their competent usage is of great importance today $[3,6,9]$.

Ethnic representations cover all the main features that help a person to understand his environment by national characteristics, both relating to his own and to someone else's national group. There are four main components that form the idea of other ethnic groups: cultural - historical, anthropological, geographical and national character and psychology, which cognitively delineate the surrounding - material, social and psychological space.

Ethnic representations are characterized by the volume or degree of representation in the consciousness of the individual, completeness, forming a system of these representations, differentiation and motivational orientations.

Thus, in the process of formation and development of ethnic ideas, a person goes from orientation to external, disparate, conspicuous signs in the division of his and someone else's ethnic group, to internal awareness and the formation of a single consistent image of his and someone else's ethnic group.

Such problems as ethnic attitudes, stereotypes, prejudices, ethnocentrism, ethnic identity, ethnic values and some others are very important for Ethnopsychology as a science.

In addition, the studies related to the concept of ethnic tolerance are no less relevant, competence occupies an important place in them - the ability to take into account the ethno-cultural "appearance" of the individual, the ability to take into account the sociocultural specificity in the course of practical activities and behavior. The understanding of the diversity of the human manifestation, caused by the ethnic system, and a particular person is a part of it, sheds light on the facts of the tolerant attitude to the representatives of other ethnic groups.

Today, we can affirm that Ethnopsychology as a science, exploring the theory and practice of different ethnic groups, is on its infancy stage: it not only explores the psychological side of the ethnic group, its mentality, but also its culture, anthropology, folklore, mythology and religion, Ethnography and language code.

The consideration of the ethnic nature and the individual is more or less complete, taking into account the signs of its manifestation as a keeper of these features. In addition, the researchers analyze the constant contacts of different ethnic groups' representatives at the cultural, social, economic and interpersonal levels, thus the development of crosscultural competence of students, which is based on the understanding and acceptance of ethnic and cultural diversity, another mentality, values and ideas, different from the usual, when it is done without strain, violence and naturally as one child in kindergarten takes another can be considered as one of the most important tasks of the education system.

At the basis of the effective development of students' cross-cultural competence some certain competencies should be formed, among which we, firstly, highlight the willingness and ability to understand the multifactorial nature of personal values and ideas, secondly, the presence of some information, that each person has his history and culture, which largely determine its psychology, worldview, behavior and activity, thirdly, the ability to independently assess a particular situation and make an adequate decision in any situation. 
Besides, such a psychological and pedagogical condition as a purposeful and systematic support of this process is important and necessary, because students will practically not be able to create the necessary cultural base, which includes at least a minimum of knowledge about a particular ethnic group, its culture, myths and traditions independently, without the external influence of organized education and teachers trained for this activity. In connection with the problem of our study, we note the expediency of cultural knowledge for each student. The cultural knowledge is mainly grouped around the following concepts: the definition of ethnicity, mental personality, mentality as an integral ethno-psychological characteristic of the individual, developing self-consciousness as a symbiosis of human and ethnic components, ethnic exclusivity and tolerance, cross-cultural characteristics of the individual and ethnic group, etc. However, theoretical knowledge, which is very important in itself, does not yet indicate a cross-cultural outlook of the individual, as the Russian Philosopher V. S. Soloviev once said: "To wish good and to do good are different things": the practical orientation of training and the formation of the necessary competencies, when there is not just awareness, but the ability and implementation in specific actions is effective.

Thus, the most important role for the modern transitive society, is played by the introduction of young people to different cultures, the acceptance of people with a different ethnic history as desirable and worthy of respect, if there are no other negative characteristics of the individual, but it has nothing to do with the ethnicity of the individual.

\section{References}

1. A.J. Umaña-Taylor, S. M. Quintana, R. M. Lee, et al., Child Dev., 85, 21-39 (2014)

2. G. Soldatova, L Shaigerova,. PS,8 (2015)

3. R.-Z. Peng, W.-P. Wu, Int. Jour. of Int. Rel., 53, 16-27 (2016)

4. W. Wang, M. Zhou, Int. Jour. of Int. Rel., 55, 1-7 (2016)

5.R. Chi, D. Suthers, Int. Jour. of Int. Rel., 48, 108-119 (2015)

6. I. Lianaki-Dedouli, J. Plouin, Fut., Article in press (2017)

7. S.B. Dagbaeva, RPsJ, 15, 140-156 (2018)

8. A. Csizmadia, A. Rollins, J. P. Kaneakua, Fam. Rel., 63, 259-270 (2014)

9. D.S. Kornienko, I.V. Gaidamashko, S.L. Kandibovich, RPsJ, 14, 109-123 (2017)

10. A.Y. Chung, From Qual.Soc., 36, 279-302 (2013)

11. M.I. Kolikhanov, E.A. Pushkar'eva, The Bulletin of NSPU, 4, 94-108 (2018)

12. G. Zahid, Soc.Beh.Sc., 174, 109-114 (2015)

13. I.R. Shields, AJour.Com.In.Ed, 46, 5-23 (2016)

14. D.E. Leidner, TJour. of Str.Inf.Sys., 19, 69-77 (2010)

15. T.D. Jules, Gl.Soc.Ed., 15, 482-498 (2017)

16. C.M. Brown, W. Ling, Ps., 3, 78-81 (2012

17. N. M. Lebedeva, A.N. Tatarko, J. Berry, Ps. Zh., 37, 92-104 (2016)

18. M.M. Hernández, R.D. Conger, R.W. Robins, K.B. Bacher, K.F. Widaman, ChD, 85, 695-708 (2014)

19. I.V. Abakumova, Z.I. Brizhak, Z.V. Masaeva, RPsJ, 13, 100-116 (2016)

20. P.M. Shamionov, N. Zh. Sultaniyazova, RPJ, 15, 157-186 (2018) 